\title{
The opening of maitotoxin-sensitive calcium channels induces the acrosome reaction in human spermatozoa: differences from the zona pellucida
}

\author{
Julio C Chávez ${ }^{1}$, Gerardo A de Blas ${ }^{1}$, José L de la Vega-Beltrán ${ }^{1}$, Takuya Nishigaki ${ }^{1}$, Mayel Chirinos ${ }^{2}$, \\ María Elena González-González ${ }^{2}$, Fernando Larrea ${ }^{2}$, Alejandra Solís ${ }^{1}$, Alberto Darszon ${ }^{1}$ and Claudia L Treviño ${ }^{1}$
}

The acrosome reaction (AR), an absolute requirement for spermatozoa and egg fusion, requires the influx of $\mathrm{Ca}^{2+}$ into the spermatozoa through voltage-dependent $\mathrm{Ca}^{2+}$ channels and store-operated channels. Maitotoxin (MTx), a Ca ${ }^{2+}$-mobilizing agent, has been shown to be a potent inducer of the mouse sperm AR, with a pharmacology similar to that of the zona pellucida (ZP), possibly suggesting a common pathway for both inducers. Using recombinant human ZP3 (rhZP3), mouse ZP and two MTx channel blockers (U73122 and U73343), we investigated and compared the MTx- and ZP-induced ARs in human and mouse spermatozoa. Herein, we report that MTx induced AR and elevated intracellular $\mathrm{Ca}^{2+}\left(\left[\mathrm{Ca}^{2+}\right]_{i}\right)$ in human spermatozoa, both of which were blocked by U73122 and U73343. These two compounds also inhibited the MTx-induced AR in mouse spermatozoa. In disagreement with our previous proposal, the AR triggered by rhZP3 or mouse ZP was not blocked by U73343, indicating that in human and mouse spermatozoa, the AR induction by the physiological ligands or by MTx occurred through distinct pathways. U73122, but not U73343 (inactive analogue), can block phospholipase C (PLC). Another PLC inhibitor, edelfosine, also blocked the rhZP3- and ZP-induced ARs. These findings confirmed the participation of a PLC-dependent signalling pathway in human and mouse zona protein-induced AR. Notably, edelfosine also inhibited the MTx-induced mouse sperm AR but not that of the human, suggesting that toxin-induced AR is PLC-dependent in mice and PLC-independent in humans.

Asian Journal of Andrology (2011) 13, 159-165; doi:10.1038/aja.2010.80; published online 13 September 2010

Keywords: acrosome reaction; calcium channels; human sperm; maitotoxin; mouse sperm

\section{INTRODUCTION}

Due to its remarkable ability to activate $\mathrm{Ca}^{2+}$ uptake, maitotoxin (MTx) has been used as a $\mathrm{Ca}^{2+}$-mobilizing agent. MTx is a 34.2-kDa non-peptidic toxin known to activate $\mathrm{Ca}^{2+}$ influx in a variety of cells. Although MTx has no ion-ophoretic activity, ${ }^{1,2}$ the actual target of MTx is not known. MTx may potentially open more than one type of channel, such as store-operated channels (SOCs) and/or transient receptor potential channels. ${ }^{3-6}$ Alternatively, MTx has been proposed to bind to the plasma membrane $\mathrm{Ca}^{2+}$ pump and convert it into a non-selective $\mathrm{Ca}^{2+}$ channel. $^{7}$

During sperm-egg interaction, at least two types of $\mathrm{Ca}^{2+}$ channels in the plasma membrane open sequentially, contributing to the $\mathrm{Ca}^{2+}$ rise observed when zona pellucida (ZP)3 (an egg coat glycoprotein) binds to its sperm receptor. ${ }^{8}$ The first type is responsible for a rapid and transient $\mathrm{Ca}^{2+}$ rise and the second provokes a sustained $\mathrm{Ca}^{2+}$ increase. The molecular identity of these two types of channels remains unclear. ${ }^{6,9,10}$ The current model includes the participation of voltagedependent $\mathrm{Ca}^{2+}$ channels and SOC/transient receptor potential channels for the first and second components of the $\mathrm{Ca}^{2+}$ rise, respectively. The opening of these $\mathrm{Ca}^{2+}$ channels is a requisite for the acrosome reaction (AR), an exocytotic event that allows spermatozoa to penetrate the outer layers of the egg and then to fuse with it. We have shown that MTx is a potential inducer of the AR in mouse spermatozoa. Our findings comparing MTx- and ZP-induced ARs indicated that the MTx- and the ZP-activated channel shared similar pharmacological profiles. ${ }^{6}$ The lack of a native human ZP has prevented a detailed study of the physiological cascade for the human AR. A few studies using recombinant or native $\mathrm{ZP}$ as well as other inducers, such as progesterone, have shown a biphasic $\mathrm{Ca}^{2+}$ response in human spermatozoa, suggesting a similar signalling cascade and signalling machinery compared with that of the mouse AR. ${ }^{11,12}$ The participation of voltage-dependent $\mathrm{Ca}^{2+}$ channels during the human $\mathrm{AR}$ is controversial, and the second type of channel is also believed to be a SOC or transient receptor potential channel with a molecular identity that has not been defined. To further characterize this process, we used MTx, recombinant human ZP3 (rhZP3) and native mouse ZP as AR inducers on human and mouse spermatozoa. We found that, although MTx and the ZP proteins induced the AR in sperm from both species, their pharmacology differed, indicating the involvement of distinct signalling pathways. 


\section{MATERIALS AND METHODS}

MTx was purchased from Wako Chemicals (Richmond, VA, USA). Fluorescein isothiocyanate-coupled Pisum sativum lectin was purchased from Sigma Chemical Co. (St Louis, MO, USA). U73122, U73343 and edelfosine were purchased from BIOMOL Research Lab (Plymouth, PA, USA). Ionomycin was purchased from Alomone (Jerusalem, Israel). Fluo-3 AM was purchased from Invitrogen (Carlsbad, CA, USA). Ham's F-10 and neomycin were purchased from Sigma Aldrich (St Louis, MO, USA). All other chemicals were of reagent grade. Stock solutions in dimethylsulphoxide were prepared for each compound, and aliquots were stored at $-20^{\circ} \mathrm{C}$.

\section{Cell preparation}

Mouse spermatozoa. Motile spermatozoa were obtained from adult CD1 male mice (3 months old). Caudal epididymal sections from a mouse were incubated in $1 \mathrm{ml}$ of Whitten's medium at $37^{\circ} \mathrm{C}$ for at least 10 min to allow motile spermatozoa to swim out. ${ }^{13}$ A $600-\mu l$ aliquot was removed, and the concentration was adjusted to $4 \times 10^{6}-$ $5 \times 10^{6}$ cells $/ \mathrm{ml}$. When needed, the spermatozoa were capacitated by incubation in medium supplemented with $5 \mathrm{mg} \mathrm{ml}^{-1}$ bovine serum albumin for $30 \mathrm{~min}$ at $37^{\circ} \mathrm{C}$ in a humid chamber with $5 \% \mathrm{CO}_{2}$.

Human spermatozoa. Ejaculates were obtained by masturbation from healthy donors after at least $48 \mathrm{~h}$ of sexual abstinence. Only samples that fulfilled the World Health Organization parameters were selected for experiments. ${ }^{14}$ Highly motile spermatozoa were recovered after a swim-up separation for $1 \mathrm{~h}$ in Ham's F-10 medium supplemented with $5 \mathrm{mg} \mathrm{ml}^{-1}$ bovine serum albumin at $37^{\circ} \mathrm{C}$ in humid chamber with $5 \% \mathrm{CO}_{2}$. The cell concentration was then adjusted to $5 \times 10^{6}-$ $10 \times 10^{6}$ spermatozoa $/ \mathrm{ml}$, and the incubation was continued for at least $4 \mathrm{~h}$ when capacitation was required.

\section{AR assays}

Mouse. After capacitation, the AR was induced incubating cells kept at $37^{\circ} \mathrm{C}$ for $30 \mathrm{~min}$ in $30-\mu \mathrm{l}$ aliquots by the addition of $5 \mathrm{nmoll} \mathrm{l}^{-1} \mathrm{MTx}$ or 5 eq $\mu^{-1} \mathrm{ZP}$ (obtained as described elsewhere ${ }^{15}$ ) in the presence or absence of inhibitors. Stock solutions of the inhibitors were prepared in dimethylsulphoxide, and the cells were preincubated with them for $15 \mathrm{~min}$ before induction. The cells were fixed by adding an equal volume of $10 \%$ formaldehyde in phosphate-buffered saline. After fixation, $10-\mu \mathrm{l}$ aliquots of the sperm suspension were spread onto glass slides and air-dried. The slides were stained with $0.22 \%$ Coomassie Blue G-250 in 50\% methanol and 10\% glacial acetic acid for $~ 5 \mathrm{~min}$, rinsed and mounted with $50 \%(\mathrm{v} / \mathrm{v})$ glycerol in phosphate-buffered saline. ${ }^{16}$ To calculate the percentage of AR, at least 100 sperm were assayed per experimental condition for the presence or absence of the characteristic dark blue acrosomal crescent.

Human. Capacitated spermatozoa were divided into 30 - to 50 - $\mu$ l aliquots. The AR was induced incubating cells kept at $37^{\circ} \mathrm{C}$ for $30 \mathrm{~min}$ by the addition of $5 \mathrm{nmol} \mathrm{l}^{-1}$ MTx or $10 \mathrm{ng} \mu^{-1}$ of purified rhZP3 (prepared as described below) in the presence or absence of inhibitors, as described above. At the end of the assay, $10 \mu \mathrm{l}$ of each sample was spotted onto slides and fixed/permeabilized in ice-cold methanol. Acrosomal status was evaluated by staining with fluorescein isothiocyanate-coupled Pisum sativum lectin according to Mendoza et al. ${ }^{17}$ Spermatozoa that have preserved an intact acrosome show strong labelling with the fluorescent lectin at the acrosomal region, while cells that have undergone acrosomal exocytosis show no labelling at the acrosomal region or labelling limited to the posterior edge of the granule (equatorial staining). At least 200 cells were counted per experimental condition. Dimethylsulphoxide controls were performed in all AR assays for both mouse and human spermatozoa.

Expression and purification of rhZP3 glycoprotein. rhZP3 was expressed in the Spodoptera frugiperda Sf9 insect ovary cell line using the baculovirus expression system as described elsewhere. ${ }^{18}$ Human ZP3 cDNA was cloned into the pAcHLT transfer vector (Pharmingen, San Diego, CA, USA), and the recombinant vector was co-transfected with a linear baculovirus into Sf9 cells using the Baculogold Transfection Kit (Pharmingen), according to the manufacturer's guidelines. The resulting recombinant virus was used for high-scale infection, and cells were harvested after 3-4 days of culture. The protein was purified using a histidine tag encoded by the pAcHLT vector. The purification process was performed as follows: (i) solubilizing cell pellets in a solution comprising $20 \mathrm{mmol}^{-1}$ Tris- $\mathrm{HCl}, \mathrm{pH} 8.0$, $0.5 \mathrm{~mol} \mathrm{l}^{-1} \mathrm{NaCl}, 5 \mathrm{mmol} \mathrm{l}^{-1}$ imidazole and $6 \mathrm{~mol} \mathrm{l}^{-1}$ guanidine hydrochloride at room temperature; (ii) centrifuging the mixture at $10000 \mathrm{~g}$ for $30 \mathrm{~min}$; (iii) adding the supernatant to a pre-equilibrated Ni-NTA resin (Invitrogen); (iv) incubating the supernatant-resin mixture overnight followed by washing with the same buffer; (v) suspending the resin in a solution comprising $20 \mathrm{mmol} \mathrm{l}^{-1}$ Tris- $\mathrm{HCl}$, $\mathrm{pH}$ 8.0, $0.5 \mathrm{~mol}^{-1} \mathrm{NaCl}, 5 \mathrm{mmol} \mathrm{l}^{-1}$ imidazole and $6 \mathrm{~mol}^{-1}$ urea; (vi) refolding the bound protein using a decreasing gradient of urea; (vii) eluting the protein with $500 \mathrm{mmol} \mathrm{l}^{-1}$ imidazole followed by dialysis against a solution comprising $20 \mathrm{mmol}^{-1}$ Tris- $\mathrm{HCl}, \mathrm{pH}$ 8.0, and $0.5 \mathrm{~mol} \mathrm{l}^{-1} \mathrm{NaCl}$; and (viii) determining the protein concentration using the bicinchoninic acid assay (Pierce, Rockford, IL, USA).

Human/mouse calculation of the acrosomal reaction index (ARI). Negative (no stimulation) and positive (stimulation with MTx or ionophore (mouse, $15 \mu \mathrm{mol} \mathrm{l^{-1 }}$ A23187; human, $10 \mu \mathrm{mol} \mathrm{l}^{-1}$ ionomycin)) controls were included in all experiments. For each experiment, ARIs were calculated by subtracting the number of reacted spermatozoa in the negative control (spontaneous AR) from all values. The resulting values were expressed as a percentage of the AR observed in the positive control (maximum AR observed with MTx except for Figure 1, in which maximum AR was obtained with each $\mathrm{Ca}^{2+}$ ionophore). For mice and humans, respectively, the AR raw percentage values were as follows: spontaneous, $17 \pm 4$ and $18.5 \pm 5$; maximum with ionophore, $67 \pm 6$ and $59 \pm 8$; and maximum with MTx, 66 44 and $55 \pm 6(n \geqslant 5)$. In all experiments, the maximum AR was observed with MTx, except for those represented in Figure 1, in which the maximum ARI was obtained with each $\mathrm{Ca}^{2+}$ ionophore.

\section{Sperm intracellular $\mathrm{Ca}^{2+}\left(\left[\mathrm{Ca}^{2+}\right]_{i}\right)$ imaging}

Capacitated human and non-capacitated mouse (used because the attachment of capacitated mouse sperm to glass cover slips for imaging is a difficult task) motile cells obtained by swim-up were incubated with $10 \mu \mathrm{mol} \mathrm{l}^{-1}$ (mouse) or $2 \mu \mathrm{mol} \mathrm{l}^{-1}$ (human) Fluo-3 AM and $0.05 \%$ pluronic acid at $37{ }^{\circ} \mathrm{C}$ for $30 \mathrm{~min}$. Spermatozoa were immobilized by the head, leaving their flagella free to move continuously, on laminin $\left(100 \mu \mathrm{g} \mathrm{ml}^{-1}\right)$ or poly-L-lysine $(0.1 \%(\mathrm{w} / \mathrm{v}))$ precoated cover slips for mouse and human spermatozoa, respectively. The cover slips were mounted on a chamber (Harvard Apparatus, Holliston, MA, USA) and placed on the stage of an inverted Nikon Diaphot 300 microscope (Nikkon Inc., El Segundo, CA, USA). Fluorescence illumination was supplied by a Luxeon V Star Lambertian Cyan LED part no. LXHLLE5C (Lumileds Lighting LLC, San Jose, CA, USA) attached to a custom-built stroboscopic control box. The LED was mounted into 

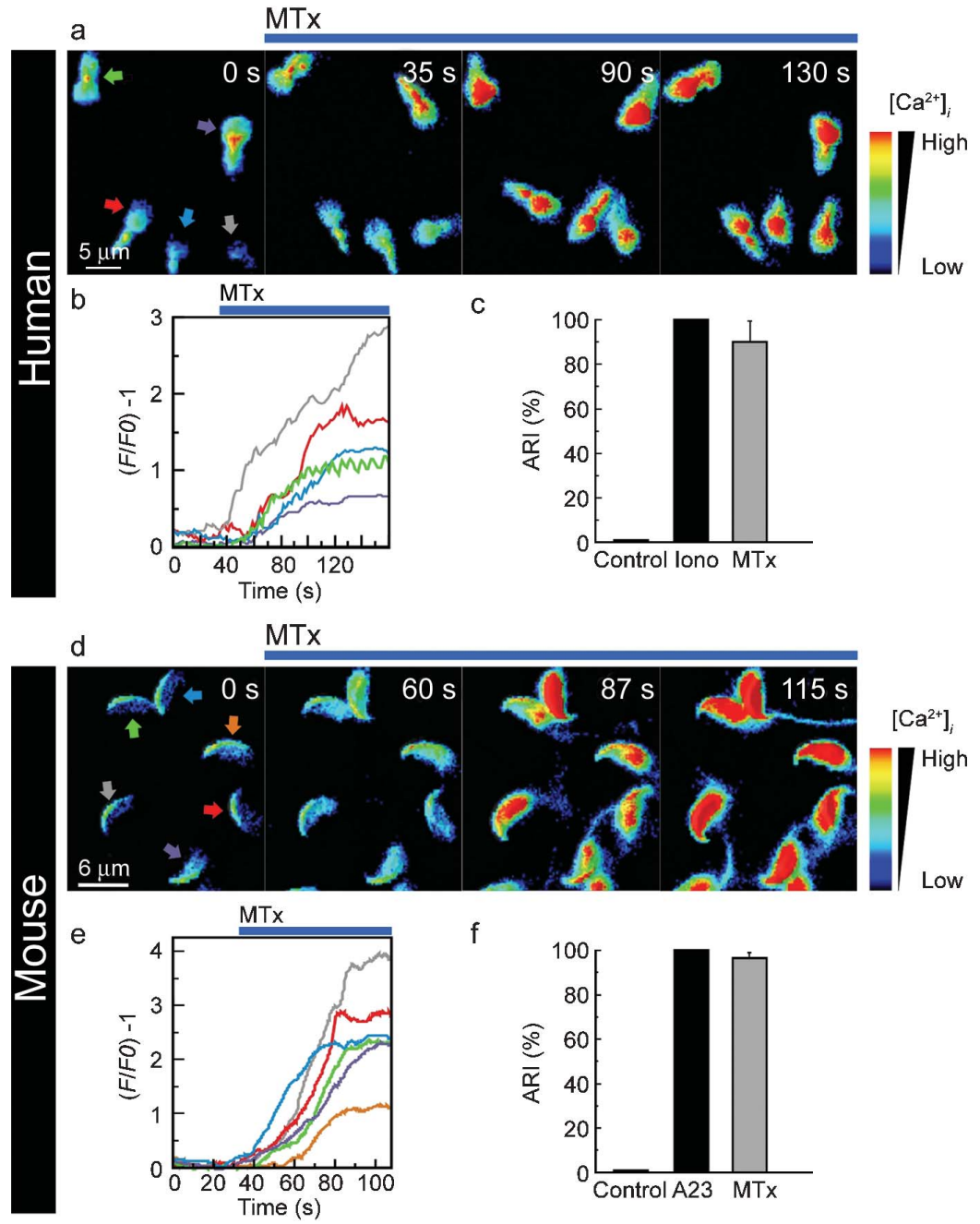

Figure 1 MTx increases $\left[\mathrm{Ca}^{2+}\right]_{i}$ and induces AR in human (a-c) and mouse (d-e) spermatozoa. Motile spermatozoa (non-capacitated) were loaded with the fluorescent $\mathrm{Ca}^{2+}$ indicator Fluo-3 AM, and the fluorescence intensity was measured before and after MTx addition, as described in the section on 'Materials and methods'. Representative single-cell spatiotemporal $\left[\mathrm{Ca}^{2+}\right]_{i}$ changes after the addition of $5 \mathrm{nmol} \mathrm{I-1} \mathrm{MTx}$ (second panel in each series) for human (a) and mouse (d) spermatozoa. Panels b and e illustrate the corresponding traces, with the cells and traces being colour coded, showing the changes in fluorescence after the addition of MTx. The time frame (s) is indicated in each panel (s). The scales indicate ( $F / F O)-1$ versus time. Approximately $95 \%$ of cells responded to MTx. The images are shown with pseudocolour, in which black to red represent low and high $\left[\mathrm{Ca}^{2+}\right]_{\text {; }}$, respectively. (c, f) Spermatozoa were capacitated for a minimum of $4 \mathrm{~h}$ (human) or 30 min (mouse). The sperm AR was induced with $5 \mathrm{nmol} \mathrm{I}{ }^{-1} \mathrm{MTx}$ or $20 \mu \mathrm{mol} \mathrm{I} \mathrm{I}^{-1}$ ionomycin (Iono) or $15 \mu \mathrm{mol} \mathrm{I}^{-1}$ A23183 for human and mouse, respectively. The data represent the mean \pm SEM from six independent experiments and were normalized as described in the section on 'Materials and methods'. AR, acrosome reaction; $\mathrm{ARI}$, acrosome reaction index; $\left[\mathrm{Ca}^{2+}\right]_{i}$ intracellular $\mathrm{Ca}^{2+} ; \mathrm{MTx}$, maitotoxin.

a FlashCube40 assembly with the dichroic mirror M40-DC400 (Rapp Opto Electronic, Hamburg, Germany) (bandwidths: excitation 450$490 \mathrm{~nm}$, dichroic mirror $505 \mathrm{~nm}$ and emission: 520-560 nm). The LED output was synchronized to the Exposure Out signal of a Cool Snap CCD camera via the control box to produce a single flash of $1 \mathrm{~ms}$ duration per individual exposure. The camera exposure time was set equivalent to the flash duration $(1 \mathrm{~ms})$. Images were collected every $250 \mathrm{~ms}$ or $1 \mathrm{~s}$ for humans and mice, respectively, using the IQ software (Andor Bioimaging, Morrisville, NC, USA) and a Plan Apo 60×/1.40 (oil) Nikon objective. ${ }^{19}$

\section{Data processing}

Fluorescence data were processed offline using the IQ software (Andor Bioimaging) and self-written Igor Programs. A region of interest was drawn around the head of each spermatozoon in the field of view. Spermatozoa that moved out of this region were discarded from the analysis. The raw intensity values were imported into Microsoft Excel and normalized using the equation $(F / F 0)-1$, where $F$ is the fluorescence intensity at time $t$ and $F 0$ is the mean fluorescence taken during the control period (initial $20 \mathrm{~s}$ ). The total series of $(F / F O)-1$ was then plotted versus time.

\section{Statistical analysis}

Statistic analyses were performed using Excel software, Microsoft Office 7. Differences between experimental and control conditions were evaluated considering unpaired, two-tailed samples and using an unpaired $t$-test. Only significant differences $(P<0.001$ and $P<0.01)$ are discussed.

\section{Cell viability}

Because U73122 affects motility, cell viability was confirmed by a visual motility inspection under a microscope or by eosin staining. 
Viability in the presence of all drugs used in this work was similar to that in the control conditions.

\section{Ethics}

The use of the animal and human samples in this study was approved by the Bioethics Committee at the Biotechnology Institute from the National Autonomous University of Mexico. All semen donors gave their written informed consent.

\section{RESULTS}

We reported previously that MTx was a potent inducer of mouse AR and that its response was blocked by $\mathrm{Ni}^{2+}$ and SKF96365 at similar concentrations to those obtained when ZP was used for induction. ${ }^{6}$ These results suggested that an MTx-sensitive channel was part of the ZP signalling cascade. During the process of characterizing the MTxinduced AR, other inhibitors were tested, and our observations were extended to human spermatozoa. Figure 1 indicates single-cell $\left[\mathrm{Ca}^{2+}\right]_{i}$ images (Figure 1a) and their respective fluorescent traces (Figure 1b) showing MTx induction of a $\left[\mathrm{Ca}^{2+}\right]_{i}$ rise in human spermatozoa. This toxin also induced the AR in capacitated human spermatozoa at the same level as the ionophore (ionomycin) (Figure 1c). Similar results were obtained with mouse spermatozoa (Figure $1 \mathrm{~d}-\mathrm{f}$ ). The MTxinduced AR was independent of capacitation in both species (data not shown).
As mentioned earlier, $\mathrm{Ni}^{2+}$ and SKF96365 were used to block the MTx-induced $\left[\mathrm{Ca}^{2+}\right]_{i}$ signal and the AR in mouse spermatozoa. ${ }^{6}$ As these substances are regarded as general inhibitors of diverse $\mathrm{Ca}^{2+}$ permeable channels, we searched for more specific inhibitors of MTxactivated channels, such as U73122 and U73343. ${ }^{20}$ Although U73122 is more commonly used as a phospholipase C (PLC) inhibitor with $\mathrm{U} 73343$ as its inactive analogue, ${ }^{21}$ there have been reports of the direct activity of U73122 on ion channels ${ }^{22}$ and the ability of both analogues to directly inhibit MTx-sensitive channels. ${ }^{20}$ Single-cell images and traces of $\left[\mathrm{Ca}^{2+}\right]_{i}$ measurements in human spermatozoa incubated in the presence of $10 \mu \mathrm{mol} \mathrm{l}^{-1}$ of each inhibitor (U73122 and U73343) followed by the addition of MTx are shown in Figure 2a. The MTxinduced response was completely abolished with both compounds, and only $\sim 5 \%$ of cells showed a minor increase. Ionomycin $\left(20 \mu \mathrm{mol}^{-1}\right)$, which served as an internal control, was added at the end of each experiment to obtain the maximum achievable signal. In the case of mouse spermatozoa, U73343 also blocked the MTx-induced $\left[\mathrm{Ca}^{2+}\right]_{i}$ rise (Figure 2b, bottom). Unfortunately, U73122 caused a rapid $\left[\mathrm{Ca}^{2+}\right]_{i}$ increase in the absence of MTx (Figure 2b, top), and the cells stopped moving their flagella, although their viability was not affected.

As anticipated, the MTx-induced human sperm AR was strongly inhibited by both drugs ( 90\%) (Figure 3a). U73343 also blocked $65 \%$ of the MTx-induced mouse sperm AR. Although U73122 by itself can induce a $\left[\mathrm{Ca}^{2+}\right]_{i}$ rise and the AR $(\sim 35 \%)$, it still significantly reduced $(P<0.01)$ the MTx-induced AR (Figure $3 \mathrm{~b}$ ). a

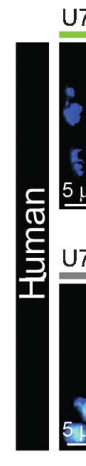

b

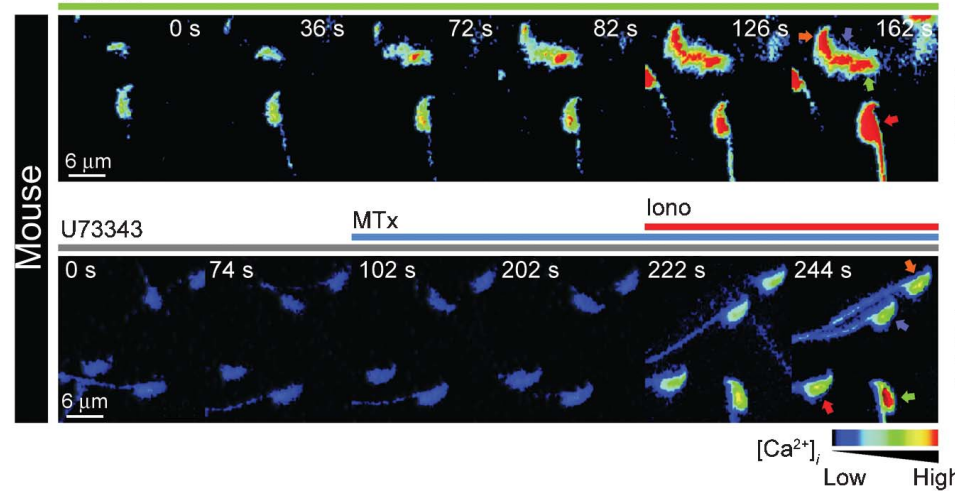

lono 20.8 lono
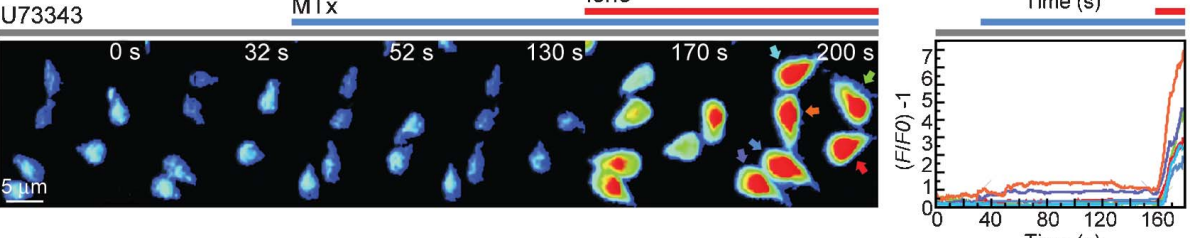

Time (s)
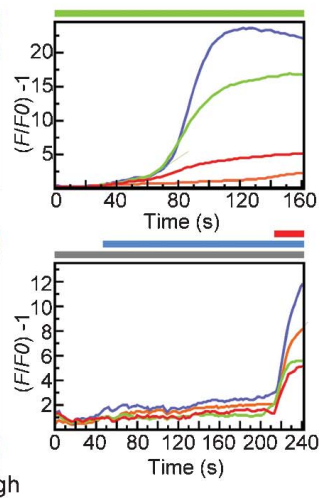

Figure 2 U73343 blocks the MTx-induced $\left[\mathrm{Ca}^{2+}\right]_{j}$ increase in human (a) and mouse (b) spermatozoa, while U73122 inhibits this response in human spermatozoa but elevates $\left[\mathrm{Ca}^{2+}\right]_{i}$ in mouse spermatozoa. Cells were isolated and loaded with Fluo-3, as in Figure 1 . Representative single-cell spatiotemporal [Ca $\left.{ }^{2+}\right]_{i}$ changes and their corresponding traces (colour coded) are shown after the addition of $5 \mathrm{nmol} \mathrm{I}^{-1} \mathrm{MTx}$ (blue line) in the presence of $10 \mu \mathrm{mol} \mathrm{I}^{-1}$ of the $\mathrm{MTx}$ activity inhibitors $\mathrm{U} 73343$ (grey line) or U73122 (green line) for human (a) and mouse (b) spermatozoa. Both inhibitors blocked the MTx-induced Ca ${ }^{2+}$ increase in human spermatozoa, but only $\mathrm{U} 73343$ blocked that response in mouse spermatozoa. Iono $\left(20 \mu \mathrm{mol} \mathrm{I}^{-1}\right)$ was added at the end of the experiments as a positive control, except in the case of panel $\mathrm{b}$, as U73122 caused a $\mathrm{Ca}^{2+}$ rise in the absence of MTx in mouse sperm. The time frame (s) is indicated in each panel (s). The scales indicate ( F/FO) - 1 versus time (s). Note: only about $5 \%$ of the cells still responded to MTx in the presence of inhibitors. The images are shown with pseudocolour, in which black to red indicate low to high $\left[\mathrm{Ca}^{2+}\right]_{i}$, respectively $(n=3) .\left[\mathrm{Ca}^{2+}\right]_{i}$ intracellular $\mathrm{Ca}^{2+}$; Iono, ionomycin; MTx, maitotoxin. 
a

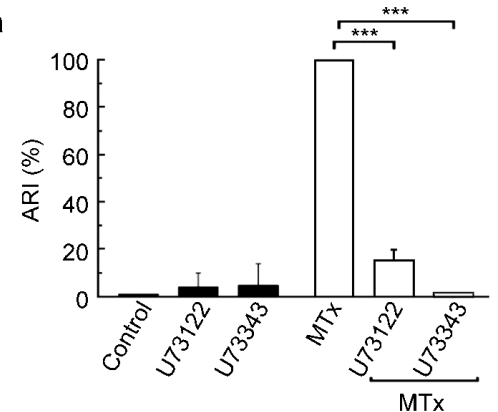

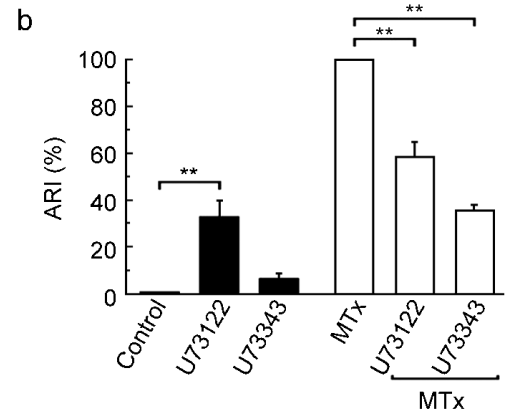

Figure 3 U73343 and U73122 block the MTx-induced AR in human (a) and mouse (b) spermatozoa. After capacitation, the AR was induced with $5 \mathrm{nmol} \mathrm{I}^{-1}$ MTx in the presence or absence of U73122 or U73343 (10 $\mu \mathrm{mol} \mathrm{I}^{-1}$ each). The ARI values for the control (solvent alone) or the inhibitors alone are also shown (black bars). The data represent the mean \pm SEM from six independent experiments and were normalized as described in the section on 'Materials and methods' (**** $P<0.001$, $* * P<0.01$ ). AR, acrosome reaction; ARI, acrosome reaction index; MTx, maitotoxin.

To further explore whether the MTx-induced AR follows a physiological pathway, U73122 and U73343 were tested in both species using rhZP3 and native mouse ZP preparations to trigger AR. If MTx opens a channel common to the ZP pathway, the rhZP3- or ZP-induced AR should be inhibited by both U73122 and U73343 in human spermatozoa and at least U73343 in mouse spermatozoa. Interestingly, U73343 could not block the ZP protein-induced AR in either the mouse or the human spermatozoa (Figure 4), as it should have if MTx activated channels were involved. In mice, U73122 alone induces a similar percentage of AR as that triggered by ZP (Figure 4b), making the results in

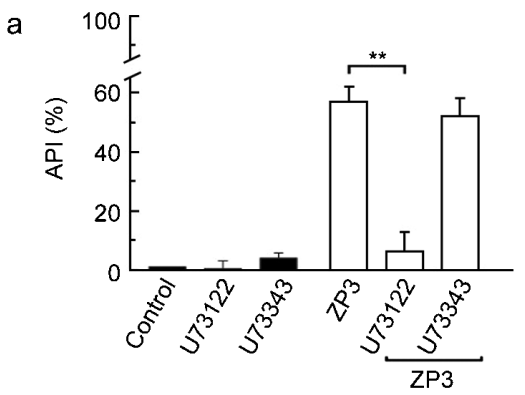

mouse spermatozoa difficult to interpret. In contrast, U73122 was able to potently inhibit the rhZP3-induced human AR (90\%). As U73122 is also a PLC inhibitor (at the concentration used), this finding is consistent with the current ZP-induced AR model, which suggested that PLC was downstream of the ZP3-binding event. Next we used edelfosine, which is another PLC inhibitor and is widely used to reveal the participation of PLC in signalling pathways, to confirm the previous result. ${ }^{23-25}$ Given that PLC acts mechanistically upstream of the SOC channels, edelfosine was not predicted to inhibit the MTx-induced AR. Edelfosine had no effect on human spermatozoa (Figure 5a),

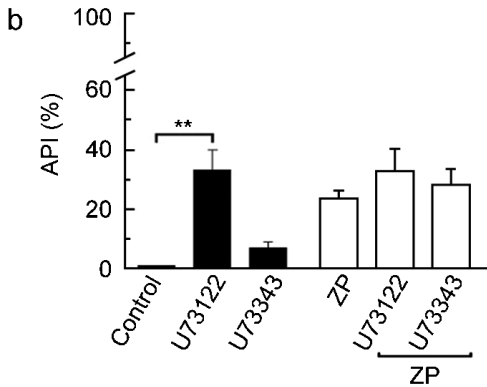

Figure 4 The physiologically induced AR was differentially sensitive to MTx inhibitors in human (a) and mouse (b) spermatozoa. The AR was induced in capacitated

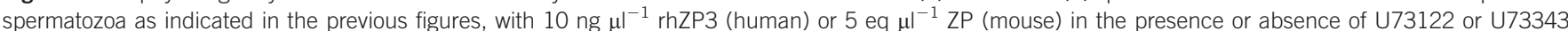
$\left(10 \mu \mathrm{mol} \mathrm{I}^{-1}\right.$ each). Controls using the inhibitors or solvent alone are also shown (black bars). The data represent the mean \pm SEM from three independent experiments and were normalized as described in the section on 'Materials and methods' (** $P<0.01)$. AR, acrosome reaction; ARI, acrosome reaction index; MTx, maitotoxin; rhZP3, recombinant human zona pellucida-3; ZP, zona pellucida.

a

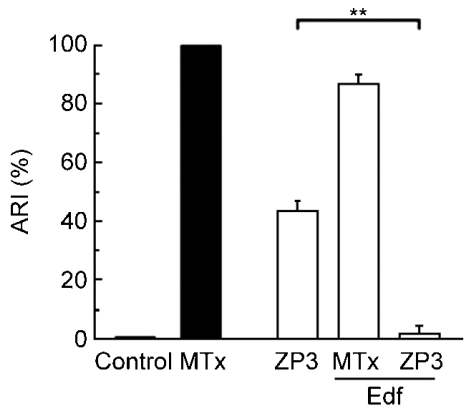

b

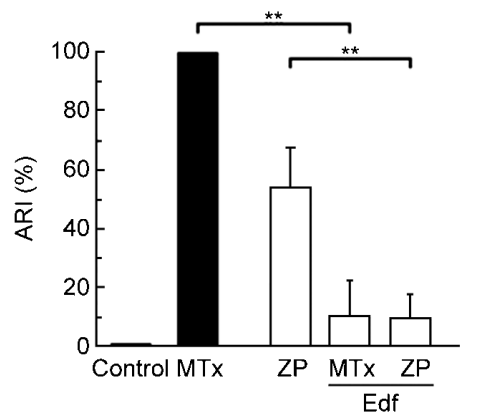

Figure 5 PLC) participates in the ZP-induced AR. The AR was induced in capacitated spermatozoa as indicated in previous figures, with $5 \mathrm{nmol} \mathrm{I}^{-1} \mathrm{MTX}$ (human and mouse), $10 \mathrm{ng} \mu \mathrm{l}^{-1}$ rhZP3 (human) or $5 \mathrm{eq} \mu \mathrm{l}^{-1} \mathrm{ZP}$ (mouse) in the presence or absence of $30 \mu \mathrm{mol} \mathrm{I}^{-1} \mathrm{Edf}$. (a) The MTx-and rhZP3-induced ARs were insensitive and sensitive, respectively, to this PLC inhibitor in human spermatozoa. (b) In mouse spermatozoa, Edf inhibited the ARs induced by both ZP and MTx. The data represent the mean \pm SEM from six independent experiments and were normalized as described in the section on 'Materials and methods' (** $P<0.01$ ). AR, acrosome reaction; ARI, acrosome reaction index; Edf, edelfosine; MTx, maitotoxin; PLC, phospholipase C; rhZP3, recombinant human zona pellucida-3; ZP, zona pellucida. 
but did inhibit the MTx-induced AR in mouse AR (Figure 5b). To confirm the role of PLC in this discrepancy, neomycin $\left(20 \mu \mathrm{mol} \mathrm{l}^{-1}\right)$, another PLC inhibitor, ${ }^{26}$ was tested, and it also blocked the MTxinduced AR in mouse spermatozoa with $50 \%$ efficiency. Neomycin did not eliminate the MTx-induced $\mathrm{Ca}^{2+}$ increase in human sperm (data not shown). As expected, the ZP protein-induced AR was inhibited by edelfosine in both species (Figure 5), confirming the participation of PLC in the physiological signalling pathway. $\left[\mathrm{Ca}^{2+}\right]_{i}$ measurements in the presence of edelfosine were not performed, since this compound interferes with Fluo-3 fluorescence.

\section{DISCUSSION}

Pharmacological tools are useful for the dissection of signalling cascades, although specificity does impose certain limitations. In this study, MTx was used to further identify the $\mathrm{Ca}^{2+}$ channels participating in the ZP signalling cascade leading to AR. Our previous results in mouse spermatozoa suggested that an MTx-sensitive channel was involved in the ZP signalling cascade. ${ }^{6}$ We sought to provide additional evidence to further characterize the MTx-sensitive channel that was participating in AR induction and extend our observations to the human model.

In this study, we showed that MTx increased $\left[\mathrm{Ca}^{2+}\right]_{i}$ and induced AR in human spermatozoa. To characterize these MTx-induced changes in the spermatozoa, compounds such as U73122 and U73343 that inhibit MTx-activated channels were used. ${ }^{20}$ In human spermatozoa, U73122 and U73343 were able to block both the MTxinduced $\left[\mathrm{Ca}^{2+}\right]_{i}$ rise and the AR. Similar results were obtained in mouse spermatozoa, even though U73122 alone increases $\left[\mathrm{Ca}^{2+}\right]_{i}$ and induces AR to a certain extent. Since U73343 alone did not produce these effects, a possible explanation would be that PLC is involved in the responses of U73122 in mouse spermatozoa. Neither edelfosine nor neomycin alone, both of which are PLC inhibitors, could induce the AR in mouse sperm, allowing the idea that there was an effect through PLC to be discarded. Alternatively, U73122 has been reported to produce side effects depending on the cell type, ${ }^{27}$ including an intracellular $\mathrm{Ca}^{2+}$ rise. For example, Jin et al. ${ }^{28}$ showed that exposure of neuroblastoma-glioma cells to U73122 caused a gradual intracellular $\mathrm{Ca}^{2+}$ increase. Another study showed that this same compound directly activates ion channels and the release of $\mathrm{Ca}^{2+}$ from intracellular stores in pancreatic acinar cells, ${ }^{22}$ indicating that these effects were not due to PLC, and the authors of this study then mentioned the possibility of protein alkylation.

The finding that U73343, which blocked MTx-induced AR in human and mouse spermatozoa, was unable to inhibit the ZP protein-induced AR in both species indicated that MTx-activated channels are not required for the $\mathrm{ZP}$-induced $\mathrm{AR}$ in these two species. These observations are important, as they do not support our previous proposal that $\mathrm{Ca}^{2+}$ channels sensitive to MTx participate in the physiological pathway of AR induction.

In mouse spermatozoa, the participation of PLC during ZP induction has been well established. ${ }^{29}$ In humans, however, the lack of sufficient native ZP3 or other human gene manipulation strategies has precluded detailed studies in this matter. In spite of this, evidence suggests the involvement of $\mathrm{G}$ proteins ${ }^{30,31}$ and $\mathrm{PLC}^{32}$ in the signalling cascade triggered by $\mathrm{ZP}$ to induce AR in human spermatozoa. Our results showing that the rhZP3-induced AR was blocked by the two PLC inhibitors tested, U73122 and edelfosine, support the participation of this lipase in the ZP-induced AR in human spermatozoa.

The PLC inhibitor edelfosine inhibited both the ZP- and the MTxinduced AR in mouse spermatozoa, which was rather puzzling. The participation of PLC is expected in the ZP-induced AR but not in the MTx-induced AR, given that the channel opened by MTx is, in principle, independent of PLC. There are previous reports showing that in particular cell types, MTx increases inositol trisphosphate production and subsequently increases $\mathrm{Ca}^{2+}$ by store depletion, supporting the participation of PLC in MTx signalling. ${ }^{33,34}$ Thus, in mouse spermatozoa, the MTx-induced AR might potentially involve PLC activation. This hypothesis was supported by our findings that the PLC inhibitor neomycin also inhibited MTx-induced AR in mouse spermatozoa. On the other hand, as edelfosine did not inhibit the MTx-induced human $\mathrm{AR}$ and neomycin did not block the MTx-induced $\mathrm{Ca}^{2+}$ rise in human spermatozoa, MTx more likely directly activates channels that conduct enough $\mathrm{Ca}^{2+}$ to trigger AR.

In summary, our results demonstrated that human sperm expresses MTx-sensitive channels. We confirmed the participation of a PLC within the signalling cascades initiated by the physiological ligand in both species and suggested a more complex mechanism for the MTxinduced AR in mouse spermatozoa. The data presented here contradict our previous hypothesis, and now we conclude that MTx and zona proteins induce the AR by different signalling cascades in both mouse and human spermatozoa. Mice can be genetically modified and are relatively easy to handle in the laboratory, making them the preferred model to study different aspects of mammalian physiology. Despite their usefulness, extrapolation to other species is not always straightforward. For example, mouse ZP contains only three glycoproteins, which is the exception among other mammals. In addition, the capacitation-associated hyperpolarization seen in mice has not been detected in human spermatozoa. Here, we report that mouse and human sperm possess MTx-activated channels with distinct properties. Further experiments are required to continue dissecting the molecular participants of the zona protein-induced AR, the molecular identity and physiological role of the MTx-activated channels present in spermatozoa and to establish the differences between species.

\section{ACKNOWLEDGMENTS}

We thank Mrs Shirley Ainsworth, Mr Juan Manuel Hurtado, Mr Roberto Rodríguez, Mrs Marcela Ramírez and Mrs Elizabeth Mata for their technical assistance. This work was supported by NIH Grant R01 HD038082-07A1 (to AD), CONACyT-México (49113 to AD, 47011 to MC, 13742 to FL and 99333 to CT) and DGAPA/UNAM México (IN211809 to AD and IN204109 to CT).

1 Takahashi M, Ohizumi Y, Yasumoto T. Maitotoxin, a $\mathrm{Ca}^{2+}$ channel activator candidate. J Biol Chem 1982; 257: 7287-9.

2 Escobar LI, Salvador C, Martinez M, Vaca L. Maitotoxin, a cationic channel activator. Neurobiology (Bp) 1998; 6: 59-74.

3 Gutierrez D, Diaz de Leon L, Vaca L. Characterization of the maitotoxin-induced calcium influx pathway from human skin fibroblasts. Cell Calcium 1997; 22: 31-8.

4 Brereton HM, Chen J, Rychkov G, Harland ML, Barritt GJ. Maitotoxin activates an endogenous non-selective cation channel and is an effective initiator of the activation of the heterologously expressed hTRPC-1 (transient receptor potential) non-selective cation channel in H4-IIE liver cells. Biochim Biophys Acta 2001; 1540; 107-26.

5 Chen J, Barritt GJ. Evidence that TRPC1 (transient receptor potential canonical 1) forms a $\mathrm{Ca}^{2+}$-permeable channel linked to the regulation of cell volume in liver cells obtained using small interfering RNA targeted against TRPC1. Biochem J 2003; 373: 327-36.

6 Trevino CL, de la Vega-Beltran JL, Nishigaki T, Felix R, Darszon A. Maitotoxin potently promotes $\mathrm{Ca}^{2+}$ influx in mouse spermatogenic cells and sperm, and induces the acrosome reaction. J Cell Physiol 2006; 206: 449-56.

7 Sinkins WG, Estacion M, Prasad V, Goel M, Shull GE et al. Maitotoxin converts the plasmalemmal $\mathrm{Ca}^{2+}$ pump into a $\mathrm{Ca}^{2+}$-permeable nonselective cation channel. Am J Physiol Cell Physiol 2009; 297: C1533-43.

8 Darszon A, Acevedo JJ, Galindo BE, Hernandez-Gonzalez EO, Nishigaki T et al. Sperm channel diversity and functional multiplicity. Reproduction 2006; 131: 977-88.

9 Xia J, Ren D. The BSA-induced $\mathrm{Ca}^{2+}$ influx during sperm capacitation is CATSPER channel-dependent. Reprod Biol Endocrinol 2009; 7: 119. 
10 Jungnickel MK, Marrero H, Birnbaumer L, Lemos JR, Florman HM. Trp2 regulates entry of $\mathrm{Ca}^{2+}$ into mouse sperm triggered by egg ZP3. Nat Cell Biol 2001; 3: 499 502.

11 Chiu PC, Wong BS, Chung MK, Lam KK, Pang RT et al. Effects of native human zona pellucida glycoproteins 3 and 4 on acrosome reaction and zona pellucida binding of human spermatozoa. Biol Reprod 2008; 79: 869-77.

12 Kirkman-Brown JC, Bray C, Stewart PM, Barratt CL, Publicover SJ. Biphasic elevation of $\left[\mathrm{Ca}^{2+}\right]_{i}$ in individual human spermatozoa exposed to progesterone. Dev Biol 2000; 222: 326-35.

13 Moore GD, Ayabe T, Visconti PE, Schultz RM, Kopf GS. Roles of heterotrimeric and monomeric $\mathrm{G}$ proteins in sperm-induced activation of mouse eggs. Development 1994; 120: 3313-23.

14 World Health Organization. WHO Laboratory Manual for the Examination of Human Semen and Sperm-Cervical Mucus Interaction. New York: Cambridge University Press; 1999.

15 Bleil JD, Wassarman PM. Autoradiographic visualization of the mouse egg's sperm receptor bound to sperm. J Cell Biol 1986; 102: 1363-71.

16 Munoz-Garay C, de la Vega-Beltran JL, Delgado R, Labarca P, Felix R et al. Inwardly rectifying $\mathrm{K}^{+}$channels in spermatogenic cells: functional expression and implication in sperm capacitation. Dev Biol 2001; 234: 261-74.

17 Mendoza C, Carreras A, Moos J, Tesarik J. Distinction between true acrosome reaction and degenerative acrosome loss by a one-step staining method using Pisum sativum agglutinin. J Reprod Fertil 1992; 95: 755-63.

18 Caballero-Campo P, Chirinos M, Fan XJ, Gonzalez-Gonzalez ME, Galicia-Chavarria M et al. Biological effects of recombinant human zona pellucida proteins on sperm function. Biol Reprod 2006; 74: 760-8.

19 Nishigaki T, Wood CD, Shiba K, Baba SA, Darszon A. Stroboscopic illumination using light-emitting diodes reduces phototoxicity in fluorescence cell imaging. Biotechniques 2006; 41: 191-7.

20 Estacion M, Schilling WP. Blockade of maitotoxin-induced oncotic cell death reveals zeiosis. BMC Physiol 2002; 2: 2

21 Evdonin AL, Guzhova IV, Margulis BA, Medvedeva ND. Phospholipase c inhibitor, u73122, stimulates release of hsp-70 stress protein from A431 human carcinoma cells. Cancer Cell Int 2004; 4: 2.

22 Mogami H, Lloyd Mills C, Gallacher DV. Phospholipase C inhibitor, U73122, releases intracellular $\mathrm{Ca}^{2+}$, potentiates Ins(1,4,5)P3-mediated $\mathrm{Ca}^{2+}$ release and directly activates ion channels in mouse pancreatic acinar cells. Biochem J 1997; 324 (Part 2): 645-51.

23 Naito Y, Okada M, Yagisawa $\mathrm{H}$. Phospholipase $\mathrm{C}$ isoforms are localized at the cleavage furrow during cytokinesis. J Biochem 2006; 140: 785-91.

24 Wong R, Fabian L, Forer A, Brill JA. Phospholipase C and myosin light chain kinase inhibition define a common step in actin regulation during cytokinesis. BMC Cell Biol 2007; 8: 15.

25 Shimizu T, Yamaguchi N, Okada S, Lu L, Sasaki T et al. Roles of brain phosphatidylinositol-specific phospholipase $\mathrm{C}$ and diacylglycerol lipase in centrally administered histamine-induced adrenomedullary outflow in rats. Eur J Pharmacol 2007: 571: 138-44.

26 Apostolakos P, Panteris E, Galatis B. The involvement of phospholipases C and D in the asymmetric division of subsidiary cell mother cells of Zea mays. Cell Motil Cytoskeleton 2008; 65: 863-75.

27 Horowitz LF, Hirdes W, Suh BC, Hilgemann DW, Mackie K et al. Phospholipase C in living cells: activation, inhibition, $\mathrm{Ca}^{2+}$ requirement, and regulation of $\mathrm{M}$ current. J Gen Physio/ 2005; 126: 243-62.

28 Jin W, Lo TM, Loh HH, Thayer SA. U73122 inhibits phospholipase C-dependent calcium mobilization in neuronal cells. Brain Res 1994; 642: 237-43.

29 Fukami K, Nakao K, Inoue T, Kataoka Y, Kurokawa M et al. Requirement of phospholipase Cdelta4 for the zona pellucida-induced acrosome reaction. Science 2001; 292: 920-3.

30 Baxendale RW, Fraser LR. Evidence for multiple distinctly localized adenylyl cyclase isoforms in mammalian spermatozoa. Mol Reprod Dev 2003; 66: 181-9.

31 Baxendale RW, Fraser LR. Immunolocalization of multiple Galpha subunits in mammalian spermatozoa and additional evidence for Galphas. Mol Reprod Dev 2003; 65: 104-13.

32 Breitbart H. Signaling pathways in sperm capacitation and acrosome reaction. Cell Mol Biol (Noisy-le-grand) 2003; 49: 321-7.

33 Venant A, Dazy AC, Diogene G, Metezeau P, Marano F. Effects of maitotoxin on calcium entry and phosphoinositide breakdown in the rabbit ciliated trachea epithelium. Biol Cell 1994; 82: 195-202.

34 Satoh E, Ishii T, Nishimura M. The mechanism of maitotoxin-induced elevation of the cytosolic free calcium level in rat cerebrocortical synaptosomes. Jpn J Pharmacol 2001; 85: 98-100. 